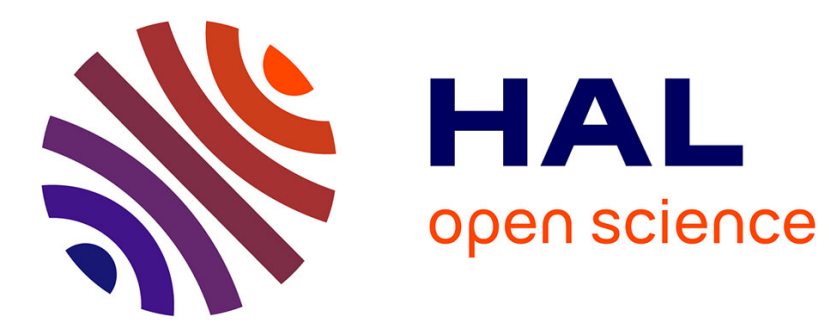

\title{
Minority language policies and politics in Nepal
}

Mark Turin

\section{To cite this version:}

Mark Turin. Minority language policies and politics in Nepal. Anju Saxena; Lars Borin. Lesser-known languages of South Asia: Status and policies, case studies and applications of information technology, 175, De Gruyter, pp.61-71, 2006, Trends in Linguistics. Studies and Monographs [TiLSM], 978-3-11018976-6. 10.1515/9783110197785.1.61 . halshs-03083343

\section{HAL Id: halshs-03083343 https://shs.hal.science/halshs-03083343}

Submitted on 19 Dec 2020

HAL is a multi-disciplinary open access archive for the deposit and dissemination of scientific research documents, whether they are published or not. The documents may come from teaching and research institutions in France or abroad, or from public or private research centers.
L'archive ouverte pluridisciplinaire HAL, est destinée au dépôt et à la diffusion de documents scientifiques de niveau recherche, publiés ou non, émanant des établissements d'enseignement et de recherche français ou étrangers, des laboratoires publics ou privés. 


\title{
Minority language policies and politics in Nepal
}

\author{
Mark Turin
}

\section{Introduction}

This article offers some structured reflections on language policies in Nepal and the associated politicization of linguistic identity. ${ }^{1} \mathrm{I}$ begin by addressing legislation dealing with linguistic diversity, and then discuss challenges to, and limitations of, the existing policies. Drawing on specific examples, I discuss the complexities of standardizing Nepal's spoken languages and the importance - for both the State and minority language communities - of developing orthographies and written traditions for Nepal's many tongues. Through this paper, I hope that policy-makers may develop a more nuanced understanding of the complexity of the ethnolinguistic fabric of modern Nepal, and that scholars will reflect for a moment on the formation and implementation of effective legislation for languages and their speakers.

\section{Legal and constitutional context}

Nepal's official linguistic policy has changed considerably over time. At present, it is in a state of flux due to the pressures exerted upon the state by ethnic advocacy movements and linguistic pressure groups on the one hand, and by the demands of the Maoist insurgents on the other. ${ }^{2}$ The Maoist leadership have demanded that all languages and dialects spoken in Nepal be set on an equal footing and that in areas where ethnic communities are in a majority, these communities should be permitted to form their own autonomous governments. The Maoists also defend the right of every citizen of Nepal to receive a secondary level education in their stated mother tongue, even though most observers view these claims as unrealistic and unworkable. In order to better understand the background to such claims, it is necessary to look at the history of language policy in Nepal.

During Panchayat rule, which ended with the restoration of democracy in 1990, the State promoted a doctrine of "one nation, one culture, one language" and the national education policy of the time was largely intolerant of indigenous and minority languages. As illustrated by the following citation from a National Education Planning Commission report, the Panchayat era policy overwhelmingly favoured Nepali: 
... and it should be emphasised that if Nepali is to become the true national language, then we must insist that its use be enforced in the primary school... Local dialects and tongues, other than standard Nepali, should be vanished [recte banished] from the school and playground as early as possible in the life of the child. (College of Education 1956: 97, as cited in Gurung 2003)

In these years, the focus was on unity rather than on diversity, and the State's preference was that Nepal be a monolingual nation speaking only Nepali. Minority languages and linguistic rights were thus consciously disregarded. Since the Panchayat era, however, the Nepali government has made significant progress in recognizing the multi-ethnic and multi-lingual nature of the nation, as indicated by the content of the Constitution of Nepal:

(a) The Nepali language in the Devanagari script is the language of the nation. The Nepali language shall be the official language.

(b) All the languages spoken as the mother language in the various parts of Nepal are the national languages of Nepal. (Article 6, Part 1)

The ambiguity of the Constitution here is notable: while Nepali is the "language of the nation" and the "official language", mother tongues spoken by indigenous peoples are "the national languages of Nepal". Some commentators see the distinction as highly nuanced, while others are critical of what they perceive to be an intentional semantic confusion based on insincere rhetoric, and they reject the claim that the Constitution of Nepal is a forward-looking and robust document (Lawoti 2003). Continuing on in the Constitution, Article 18 of Part 3, in the section on Fundamental Rights, states that:

(c) Each community residing within the Kingdom of Nepal shall have the right to preserve and promote its language, script and culture.

(d) Each community shall have the right to operate schools up to the primary level in its own mother tongue for imparting education to its children.

While the combination of Articles 6 and 18 provides a solid constitutional bedrock for linguistic minorities to have access to mother tongue language instruction, it remains unclear from Article 18 (2) whether the "right to operate schools" is one which will be underwritten by government financial aid.

The constitutional guarantee of Article 18 was not entirely new for Nepal, even though its precise formulation in the post-democracy constitution of 1990 was a significant departure. Article 7 of the 1971 Education Act of Nepal already stated that: 
(e) The medium of instruction in schools shall be the Nepali language.

(f) Provided that education up to the primary level may be imparted in the mother tongue.

On October 16, 2001, five Members of Parliament (MP) of the House of Representatives presented a Non-Governmental Bill Relating to the Management of Languages. While this bill followed up the provisions enshrined within the Constitution relating to issues of visibility, documentation, and cultural preservation, an important new recommendation was for a "three-language policy" including the mother tongue, a second language (Nepali), and an international language (most likely English). This recommendation was presented as being very much in line with emerging research and international best practices in education which demonstrate that trilingual education, when implemented with due care and attention in multilingual nations, may help to make children comfortable in a range of languages applicable in different social contexts.

\section{Policy failure and challenges to the state}

The constitutional ambiguity described above set the stage for a number of linguistic tensions in Nepal. There are no shortage of national and international provisions for what may be termed "linguistic rights", and many indigenous peoples' groups and activist organizations in Kathmandu are fully aware of these rights as enshrined in the Constitution, the Education Act and its Amendments, and the recommendations of the various governmental reports which address these issues. The real concern relates to the ability of such groups - and particularly the indigenous people and linguistic minorities of rural Nepal whom they claim to represent - to gain access to, and then effectively use, the legal system to defend their basic linguistic and social rights. Aside from one prominent case discussed immediately below, language activists do not commonly evoke legal provisions to defend their rights; and debates about language, ethnicity, and culture are generally not acted out in courts.

The case in question relates to a decision made by three local administrative bodies between August and November 1997 - the Kathmandu Metropolitan City, Dhanusha District Development Committee and Rajbiraj Municipality - to use local languages (Newar and Maithili respectively) as official languages in addition to Nepali. This right had been enshrined in the Local Self-Governance Act of 1999, which deputed to local bodies the right to use, preserve, and promote local languages. The decision by these three local 
bodies to use regional languages was legally challenged and cases were filed in the Supreme Court of Nepal, after which an interim order was issued on March 17, 1998, prohibiting the use of local and regional languages in government administration. This order led to much discontent and resentment among minority communities, and a number of action committees were promptly formed to address the ruling. On June 1, 1999, the Supreme Court nevertheless announced its final verdict and issued a certiorari declaring the decision of the local administrative bodies to use regional languages to be unconstitutional and illegal. The court's verdict raised serious questions about the sincerity of the government's commitment to the use of minority languages in administration, and further increased resentment among minority language communities. Public demonstrations and mass meetings were called, and the Nepal Federation of Nationalities (NEFEN) organized a national conference on linguistic rights on March 16-17, 2000 with support from the International Work Group on Indigenous Affairs (IWGIA). The proceedings of this conference were published in April 2000. Four resolutions were adopted during the conference, one of which demanded that:

...legal provisions be made to allow the use of all mother-tongues and the verdict of the court be declared void since it runs against the values of the present Constitution of Nepal which recognises all mother-tongues as "national languages" and the Local Autonomy Act [LSGA] of 2055 which contains provisions for the use, preservation and promotion of mother-tongues by local bodies. (Nepal Federation of Nationalities 2000: 8)

As illustrated by the above example, ethnolinguistic issues in Nepal are highly politicized and many activists feel powerless to guarantee their rights in the face of government opposition and hypocrisy. Disagreements also exist between different indigenous peoples' movements on the correct path to achieve equality. At opposing ends of the continuum are those advocates who propose working to change the system from within, and militant organizations who have allied themselves with the Maoist movement, believing that parliamentary debate will not deliver practical results at the grassroots level. The middle ground, however, is occupied by a plethora of organizations who support minority rights, but who are losing faith in the government's ability to bring about any meaningful change.

There is widespread concern among language activists and villagers from indigenous communities that despite the countless legal provisions respecting their fundamental linguistic rights, an institutional inertia exists regarding the emotive issues of mother tongue education and the access granted to minority communities to positions in government and the administration. Indigenous 
people and minority language communities have highly restricted access to the existing legal provisions to defend their rights, particularly in rural areas poorly serviced by infrastructure, and are intimidated by the very institutions which are meant to represent and protect them. As Sonia Eagle has written, "in Nepal, language issues may be seen as representative of the broader issues of powerlessness, prejudice, and inequality felt by minority groups throughout the country" (1999: 322).

While the situation is naturally complex, there are three principal reasons why linguistic minorities rarely resort to legal means to defend their rights. First, the machinery of government is still primarily controlled by high caste groups who have held power for the last 250 years, and have little incentive to change or relinquish control. Second, educated indigenous peoples in both urban and rural Nepal are reluctant to use official channels - legal or administrative - to redress inequalities since they believe the system itself to be weighted against their interests and their chances of success limited. This is a realistic concern, as illustrated by the rulings against Newar and Maithili illustrated above, particularly since fluency in spoken Nepali and a high degree of literacy are prerequisites for legal exchange, skills which many linguistic minorities still do not have. In a recently published paper, the British scholar Bryan Maddox illustrates how the most acute forms of linguistic inequality are experienced by the least educated and literate groups in society, and by a minority of monolingual communities who are not able to access the languages of power. Third, many indigenous peoples and linguistic minorities in rural areas are simply not aware of their rights, or if they are, they have no practical knowledge of how and where to best assert them. The above factors, combined with widespread discrimination against minority populations, have effectively inhibited the development and inclusion of ethnic and linguistic minorities within the Nepali nation.

Given the disjuncture between the legal and constitutional provisions for linguistic equality on the one hand, and the reality of the overwhelming dominance of Nepali on the other, it is easy to understand the frustrations and despair of activist groups representing minority communities. The crisis lies not in the formulation of policy, but in the ability and desire of the governing classes to actively change the status quo. ${ }^{3}$

\section{The importance of orthography and written tradition in the formation of linguistic policy in Nepal}

While all but eight of the many languages spoken in Nepal as mother tongues have no literate tradition, in its report to the government on April 14, 1994, 
Nepal's National Language Policy Recommendations Commission presented a four-fold stratification of languages spoken in Nepal ranked on the basis of having a written form. At the top, in first position, were those languages with elaborate and well-attested written traditions, such as Nepali, Newar, Maithili, Limbu, Bhojpuri, and Awadhi. In second position came languages "in the process of developing a written tradition" such as Tamang, Gurung and various others (Sonntag 2001: 169). In third position came those languages without a written tradition, while the "dying" languages, such as Raute, were listed last. In this hierarchical caste-system of languages, script and literacy are the highest units of value, and "written languages" are accorded a higher status than spoken ones. The educational and linguistic agendas of the Nepalese state thus converge around the issues of script and orthography: languages with a written tradition and a history of literature are promoted and supported above endangered spoken forms.

Noting the Commission's ranking of languages according to their possession, development, or evolution of a written form, it comes as no surprise to learn that ethnoactivists and promoters of indigenous languages have adjusted their programmes accordingly. Language development activities, many of which seek national recognition and funding, now commonly include some of the following components: "graphization" or the establishment of an orthography and spelling conventions; "standardization" the process of making one speech variety a "super-dialectal" norm, and "modernization", the extension of the lexicon to cope with the experiences of the modern socio-linguistic world (Webster 1999: 556). Since the mid-1990s, the lexicalization of a language and the development, or resurrection, of a suitable script or set of orthographical conventions have become prerequisites for introducing a language into education as the medium of instruction, the latter being a primary aim of both many language activists and a major component of contemporary linguistic policy in Nepal. International donors are at present engaged in lengthy negotiations with His Majesty's Government of Nepal (HMG/N) to assure that the forthcoming five-year plan for education, dubbed Education for All 2004-2009, will address the needs of Nepal's ethnic and linguistic minorities. While the Core Document of EFA 2004-2009 prepared by the Ministry of Education and Sports (MOES) points out that "programmes that provide education in mother tongues will be encouraged in order to increase access of children from diverse linguistic groups" (2003: 18) and that the Curriculum Development Centre has "succeeded in developing curriculum and textbook materials in eleven minority languages" (2003: 25), donors and linguistic activists remain sceptical of the government's commitment to effective implementation of such pilot projects. 
A few general issues relating to language documentation and lexicalization are worth noting. First, the process of standardization required for a pedagogical grammar, textbook, or dictionary necessarily results in a degree of language simplification. Just as divergent spellings of words and regional variations of speech were constrained by the standardization of English grammar and spelling by Samuel Johnson, so too the development of writing systems for Nepal's indigenous languages are resulting in the standardization of the spoken language and the concurrent elevation of one speech variety to a normative position above others. There are various dialects or speech varieties of Thakali and Tamang, for example, and in the process of developing a suitable writing system and corpus of pedagogical materials in the language, one variety (or a synthetic mixture of both) will necessarily be promoted as standard and representative. Given the highly diverse and heterogeneous ethnolinguistic tapestry of Nepal in particular, and the Himalayan region in general, the process of linguistic standardization can be expected to be complicated. Studies of identity politics have shown that minority groups the world over may sooner learn a national or international language than adjust their own speech forms to resemble that of their immediate neighbours.

Second, when oral languages are standardized and written forms are created, a speech community must either choose to use an existing script or to invent an entirely new one. Various scripts exist within Nepal, the two dominant ones being the Nepali, or Devanagari script, and the Tibetan script. Other languages with pre-existing and unique scripts include Newar, Limbu and Lepcha. Indigenous peoples speaking languages without a literate tradition generally choose between three options when developing a writing system: using the Devanagari script, using the Tibetan script, or devising a new script.

The strength of the Nepali/Devanagari script is that it is widely recognized and understood by citizens from different ethnic backgrounds, largely on account of the growth of primary education and the boom in print media since 1990. The disadvantage is that the phonetic basis of the Devanagari script imposes orthographical constraints on the sounds it is able to represent. ${ }^{4}$ In addition, many of the indigenous communities in Nepal who speak TibetoBurman languages are reluctant to use a script derived from an Indo-Aryan language to which their language is genetically unrelated. The "Nepalification" through script or lexicon of indigenous Tibeto-Burman languages is strongly resisted by many more militant members of the ethnic movement in Nepal.

The advantage of the Tibetan script, on the other hand, is that it derives from a language in the same language family as many of Nepal's indigenous 
and unwritten Tibeto-Burman languages. Some phonological features of Nepal's extant Tibeto-Burman languages may therefore be more easily represented using the Tibetan script. At a symbolic and political level, 'Tibetanness' makes reference to a cultural heritage alternative to the dominant traditions embodied by Hindu Nepal. The disadvantages of choosing the Tibetan script, however, are overwhelming. Most of Nepal's Tibeto-Burman languages are far removed from modern spoken and written Tibetan, both in terms of grammar and phonology. Membership in the same language family in no way guarantees linguistic similarity or the applicability of one script for all languages in the group. The complex spelling rules of modern Tibetan are also entirely inapplicable to unwritten languages which have no classical literary form, as the Sherpa and Tamang communities of Nepal have learned at their peril.

Finally, some indigenous peoples of Nepal are developing new scripts for their mother tongues. While these attempts are laudable, they are also often unrealistic given the generally poor level of educational attainment of those involved in the process and the practical challenges in disseminating new scripts (publishing outlets, computer fonts, special schools). There are few professionally-trained lexicographers or linguists among those indigenous activists working on the development of scripts or compiling language corpora for Nepal's endangered languages. The desire for a script is an understandable aspiration for minority language communities given the psychological link often made between script $=$ literate tradition $=$ classical language $=$ recorded history $=$ cultural authenticity and power. Some linguistic activists in Nepal see the development of a script for their language as primarily important for the status that this will accord their community on the national stage, as in gaining a higher ranking in the Language Commission's table, rather than for any resulting mother tongue or bilingual education programme that may ensue.

The challenge of finding the "right" script can be illustrated through examples. Thangmi is a Tibeto-Burman language spoken by little more than 30000 people, most of whom are resident in the Dolakha and Sindhupalcok districts to the east of Kathmandu. While most Thangmi speakers are reconciled to using a slightly modified form of the Devanagari script to write their mother tongue, and also believe that they never had their own unique writing system, some of the more active members of the community are eager to unearth any indication of a uniquely Thangmi script. I have often heard it said that the Thangmi language once had its own script but has since lost it, a kind of fall from linguistic grace. ${ }^{5}$ Such a belief reflects the widespread, if mistaken, assumption that all "real" languages were once written as well as spoken and 
that only through recovering a lost script will the Thangmi language activists be able to validate their claims to linguistic antiquity and autochthony in the areas which they presently inhabit.

Tamang, on the other hand, is spoken by over 1 million people or $5.19 \%$ of the total population, making it one of Nepal's most widespread ethnic languages. The Nepal Tamang Ghedung, an ethnic organization representing Tamang concerns at a national level, writes its name in three scripts: Nepali (Devanagari) for the benefit of most ethnic Tamangs who are functionally literate and have passed through the Nepali education system; a modified Tibetan script (dispensing with the complicated spelling conventions) on account of the language's place in the Tibeto-Burman language family and also because a growing number of Tamang Buddhists are versed in the Tibetan script; and English for the international or western educated audience. Such a tri-scriptural approach, while catering to all parties, is clearly pragmatically unworkable as a long term solution.

\section{Conclusion}

Over the last half century, Nepal's approach to legislating language policy and accounting for linguistic rights has seen a marked improvement. Moving from a "one nation, one language" model promoted through the 1950s, there was a noticeable move towards encouraging and supporting Nepal's indigenous languages and the communities who speak them by the time that democracy was restored to Nepal in 1990. While the constitution of Nepal enshrines a number of linguistic rights for minorities, and while the government is signatory to various international agreements, few if any of the promises and constitutional rights have been actively pursued or implemented, and the government's commitment to linguistic rights continues to be theoretical rather than practical.

Regrettably, the disjuncture between rights and reality has only served to further politicize, and radicalize, the already embittered linguistic minorities, many of whom no longer believe government pledges on mother tongue education and bilingual classrooms. Furthermore, the extreme focus on writing systems and the associated push to develop suitable orthographies for spoken languages has done little to offer practical support for Nepal's home-grown diversity of spoken tongues. It is an unfortunate paradox that while previously unwritten languages are being standardized and are developing written forms, the number of mother tongue speakers of many of these languages continues to fall. It appears that some graphization programmes are missing the wood for the trees by emphasizing standardization and centralization rather than linguistic fluidity and dynamism which spoken languages need to survive. 
Recognizing that many minority language communities have accepted the idea that a "proper" language must be written, I have addressed some of the motivations which inform decisions for or against the use of certain scripts in the representation of these languages. While it is likely that many of Nepal's minority languages will be reduced from communicative vernaculars to symbolic, albeit written, markers of identity within a generation, this loss should not overshadow language revival activities such as those described by Noonan in this volume and in Turin (in press). The cultural values and political valences attached to languages are dynamic and changing, rather like linguistic forms themselves. Scholars and policy makers would do well to recognise this and to develop analytical tools and legislative amendments which are robust and yet flexible enough to make sense of Nepal's shifting ethnolinguistic reality.

\section{Notes}

1. I am grateful to Professor Dr. George van Driem, Dr. Daniel Barker, Dr. Anju Saxena, and Sara Shneiderman for their valuable comments on earlier versions of this paper. Sections of this paper were presented at the Agenda of Transformation: Inclusion in Democracy conference in Nepal in April 2003, then under the title "The many tongues of the nation: ethnolinguistic politics in post-1990 Nepal".

2. In August 2004, the official number of dead passed the 10000 mark, making Nepal's Maoist-State conflict the deadliest civil war in Asia at present (Newar 2004: 1).

3. Maddox concludes that a language policy simply based on the promotion of the mother tongue would not be subtle enough to respond to Nepal's linguistic diversity.

4. A recent paper by Michael Noonan, available as a downloadable PDF from his website <http://www.uwm.edu/ noonan/>, addresses recent adaptations of the Devanagari script for the Tibeto-Burman languages of Nepal.

5. Thangmi ritual practitioners or shamans, known as guru, narrate an origin tale in which Thangmi ancestors were once so close to starvation that they ate their religious texts out of desperation, thereby losing the original and unique Thangmi script and retaining only the spoken form of the language.

\section{References}

Eagle, Sonia

1999 The language situation in Nepal. Journal of Multilingual and Multicultural Development 20 (4-5): 272-327.

Gurung, Yogendra Bahadur

2003 Indigenous Peoples Development Plan for Rural Water Supply and Sanitation (RWSS-II). Kathmandu: Institute for Social and Gender Equality. 
His Majesty's Government of Nepal

2003 Education for All 2004-2009: Core Document. The Ministry of Education and Sports, Kathmandu, Nepal. 17 November 2003.

Lawoti, Mahendra

2003 Inclusive democratic institutions in Nepal. Paper presented at The Agenda of Transformation: Inclusion in Nepali Democracy conference. Social Science Baha, Kathmandu, 24-26 April, 2003.

Maddox, Bryan

2004 Language policy, modernist ambivalence and social exclusion: A case study of Rupendehi district in Nepal's Tarai. Studies of Nepali History and Society 8 (2): 205-224.

Nepal Federation of Nationalities

2000 Proceedings of the National Conference on Linguistic Rights in Nepal. Kathmandu: Triyuga Offset Press.

Newar, Naresh

2004 10,000+. Nepali Times, No. 209, 13-19 August 2004: page 1.

Sonntag, Selma K.

2001 The politics of determining criteria for the languages of education in Nepal. In Droit et langue(s) d'enseignment: Law and Language(s) of Education, Thomas Fleiner, Peter H. Nelde, and Joseph-G. Turi (eds.), 161-174. Bâle: Helbing and Lichtenhahn.

Turin, Mark

in press Rethinking Tibeto-Burman: Linguistic identities and classifications in the Himalayan periphery. In Tibetan Borderlands: Proceedings of the Tenth Seminar of The International Association of Tibetan Studies, Christiaan Klieger (ed.). Leiden: Brill.

Webster, Jeff

1999 The language development-language promotion tension: a case study from Limbu. In Topics in Nepalese Linguistics, Yogendra P. Yadava, and Warren W. Glover (eds.), 556-565. Kathmandu: Royal Nepal Academy. 
